\title{
Adsorption of Triton X-100 and cetyltrimethylammonium bromide mixture with ethanol at nylon-6-solution interface with regard to nylon-6 wettability: I. The effect of adsorption on critical surface tension of nylon-6 wetting
}

\author{
Magdalena Bielawska • Bronisław Jańczuk • \\ Anna Zdziennicka
}

Received: 17 October 2012/Accepted: 24 December 2012/Published online: 15 January 2013

(C) The Author(s) 2013. This article is published with open access at Springerlink.com

\begin{abstract}
The contact angle measurements of the aqueous solutions of $p$-(1,1,3,3-tetramethylbutyl)phenoxypoly(ethylene glycol) (TX-100) and cetyltrimethylammonium bromide (CTAB) mixture with ethanol on nylon- 6 were made in the range of the total concentration of CTAB and TX100 mixture from $1 \times 10^{-6}$ to $1 \times 10^{-3} \mathrm{M}$ and ethanol from 0 to $17.13 \mathrm{M}$. In the CTAB and TX-100 mixture the mole fraction of TX-100 was equal to $0 ; 0.2 ; 0.4 ; 0.6 ; 0.8$ and 1 . On the basis of the obtained results, the critical surface tension of nylon-6 wetting was determined from the dependence of cosine of contact angle and the adhesion tension as a function of the surface tension of the solution. This tension was compared to the components and parameters of nylon-6 surface tension taken from literature and discussed in the light of the surface excess concentration of the surface active agents at the nylon-6-solution interface calculated from the Lucassen-Reynders equation and the Gibbs isotherm.
\end{abstract}

Keywords Nylon-6 - Triton X-100 - CTAB - Ethanol · Wetting · Contact angle · Gibbs surface excess concentration

Electronic supplementary material The online version of this article (doi:10.1007/s10450-012-9465-4) contains supplementary material, which is available to authorized users.

M. Bielawska · B. Jańczuk · A. Zdziennicka $(\bowtie)$ Department of Interfacial Phenomena, Faculty of Chemistry, Maria Curie-Skłodowska University, Maria Curie-Skłodowska Sq. 3, 20-031 Lublin, Poland

e-mail: aniaz@hektor.umcs.lublin.pl

\section{Introduction}

The process of the surface wetting plays an extremely important role in everyday life and industry because the usefulness of many products like inks, adhesives, paints or cosmetics depends on the effective spreading of the wetting liquid on the solid surface (Rosen 2004; Tadros 1994; Leja 1982; Tandford and Reynolds 1976).

Wetting of the solid by a liquid depends on the functional groups on the solid surface as well as the volumetric and surface properties of the wetting liquid. As a wetting liquid, water is the most commonly applied, but because of its high surface tension, various surface active agents are added to the solution (Rosen 2004). They lower the surface tension of the liquid and change the solid-liquid interfacial tension to such a degree that the complete spreading of the liquid on the solid surface may occur. The multicomponent surfactant systems are usually applied because they often show a synergetic effect in the water surface tension reduction in comparison to the single-surfactant solutions at the same concentration (Rosen 2004; Szymczyk 2011, 2012; Szymczyk and Jańczuk 2010; Bielawska et al. 2012). Moreover, there are many organic and inorganic additives which can modify the volumetric and surface properties of the wetting liquid and the short-chain alcohols like methanol or ethanol are the most popular among them (Rosen 2004; Zana 1995; Zdziennicka 2009a, 2010a). Depending on their concentration in the solution they can be treated as cosurfactants or cosolvents and their activity at the solidsolution interface is strongly related with the number of the carbon atoms in their chain and its branching (Rosen 2004; Zana 1995; Zdziennicka 2009a, 2010b). Taking the literature data into account (Zdziennicka 2009b, Zdziennicka and Jańczuk 2010), it seems that the addition of the shortchain alcohol to the aqueous solutions of the mixture of 
two classical surfactants may strongly improve the wettability of the solid by these solutions by enhancing the synergetic effect in the water surface tension reduction. One of the most important physicochemical quantities characterizing the wetting process is the critical surface tension of the solid wetting $\left(\gamma_{C}\right)$, developed by Zisman (1964). The knowledge of $\gamma_{C}$ can be useful for the prediction of the wettability of a given solid by the proper liquids or the solutions. It is particularly important to know the $\gamma_{C}$ of the solid wetting by the aqueous solutions of the mixture of surface active agents. Thus, many studies can be found dealing with the wettability of different solids by such kind of solutions but it is difficult to find such studies for nylon-6 (Rosen 2004; Tadros 1994; Zisman 1964; Adamson and Gast 1997; Blake 1984). The improvement of the nylon- 6 wettability is necessary in many cases because of its wide practical application (for example in the manufacture of nets, ropes or surgical sutures).

For that reason we investigated the wettability of nylon6 by the aqueous solutions of the mixture of two classical surfactants: cationic cetyltrimethylammonium bromide (CTAB) and nonionic Triton X-100 with ethanol in a wide range of the surfactant mixture concentration and in the whole ethanol concentration range, so that both ethanol and surfactants occurred in the solution in the monomeric or aggregated form.

\section{Materials and methods}

\subsection{Materials}

$p$-(1,1,3,3-tetramethylbutyl)phenoxypoly(ethylene glycol) (TX-100) obtained from Fluka and CTAB purchased from Sigma-Aldrich were used without any further purification. Ethanol (99 \% purity) obtained from Sigma-Aldrich was purified by fractional distillation in the presence of magnesium and iodine as an activator (Vogel 2006) and kept over molecular sieves. All the solutions were made using doubly distilled and deionised water (Destamat Bi18E) and its purity was controlled by the surface tension measurements before the solution preparation. The series of the aqueous solutions of TX-100 and CTAB mixture with ethanol at the constant total concentration of the surfactant mixture equal to $1 \times 10^{-6}, 1 \times 10^{-5}, 1 \times 10^{-4}$ and $1 \times 10^{-3} \mathrm{M}$, containing the mole fraction of TX-100 equal to 0 (aqueous solutions of CTAB and ethanol mixture); 0.2 ; $0.4 ; 0.6 ; 0.8$ and 1 (aqueous solutions of TX-100 and ethanol mixture), and alcohol concentration ranging from 0 to 17.13 M, were prepared.

The nylon- 6 plate was prepared and cleaned according to the procedure described in the literature (Jańczuk and Białopiotrowicz 1989). The quality of its surface was controlled by a polarizing microscope (Nikon, ECLIPSE E 600 POL) and next the selected plates without cracks and roughness were additionally controlled by the contact angle measurements on the four sides of the water drop settled on the nylon- 6 surface. If the differences between the values of the contact angle measured on different sides of the water drop did not exceed $\pm 1^{\circ}$ and the average value of the obtained contact angle was close to those in the literature (Szymczyk et al. 2012) then such plates were used for investigations.

\subsection{Contact angles measurements}

The measurements of the advancing contact angles of the aqueous solutions of TX-100 and CTAB mixture with ethanol on the nylon- 6 surface were made using the sessile drop method with the telescope-goniometer system at $25 \times$, in a thermostated chamber at $293 \pm 0.1 \mathrm{~K}$. For each solution at least 30 independent drops were used for the determination of the average values of the advancing contact angles and they were obtained with good reproducibility. The standard deviation for each set of values was less than $\pm 1.1^{\circ}$.

\section{Results and discussion}

\subsection{Contact angle isotherms}

The contact angle isotherms of the aqueous solutions of Triton X-100 and CTAB mixture with ethanol on the nylon-6 surface obtained in the whole range of ethanol concentration and the wide range of surfactant mixture concentration indicate that the biggest changes of the contact angle values in the studied systems occur if both the alcohol and surfactants are present in the monomeric form in the solution (Figs. 1, 2, 3, 4) (Rosen 2004; Zana 1995; Zdziennicka et al. 2012; Czerniawski 1966; Carpena et al. 2002; Barchlui and Pottel 1994; Das and Das 2009; Nagarajan and Wang 2000; Kumbhakar et al. 2004; Rhabi and Winnik 2001; Musselman and Chander 2002; Jones 1999; Yano 2005; Kahlweit et al. 1991). In the range of ethanol concentration in which it can form small aggregates in the solution, the contact angle values practically do not depend on the composition and concentration of the surfactant mixture. It is interesting that the complete spreading of the studied solutions on the nylon- 6 surface takes place nearly at the same value of the surface tension independently of the composition and concentration of the surfactant mixture $(26.7-28.6 \mathrm{mN} / \mathrm{m})$.

The basis for understanding the nylon- 6 wetting by the aqueous solutions of TX-100 and CTAB mixture with ethanol is the Young's equation (Adamson and Gast 1997): 


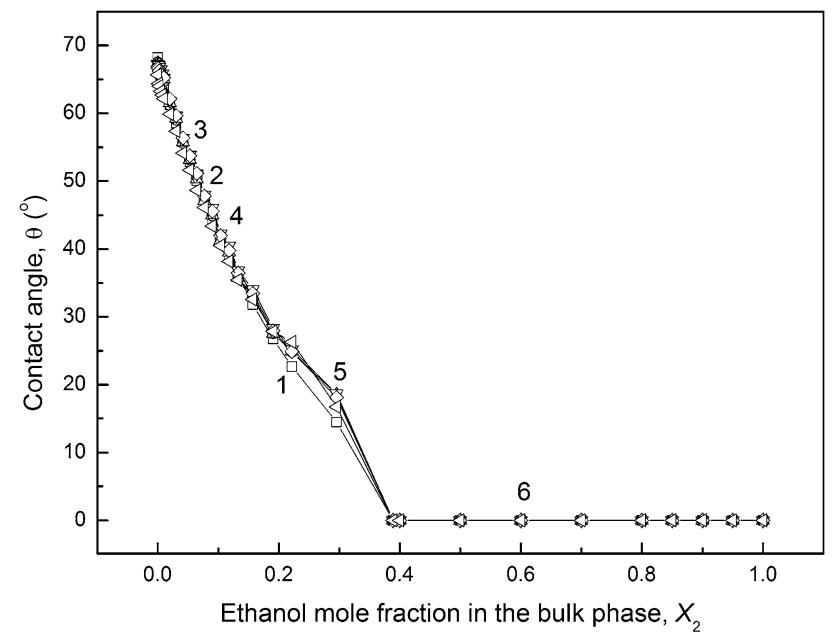

Fig. 1 The plot of the contact angle $(\theta)$ of the aqueous solutions of the TX-100 and CTAB mixture with ethanol at the constant total concentration of the TX-100 and CTAB mixture equal to $1 \times 10^{-6} \mathrm{M}$ versus ethanol mole fraction in the bulk phase $\left(X_{2}\right)$. Curves 1-6 correspond to the mole fraction of TX-100 in the mixture with CTAB equal to $0 ; 0.2 ; 0.4 ; 0.6 ; 0.8$ and 1 , respectively

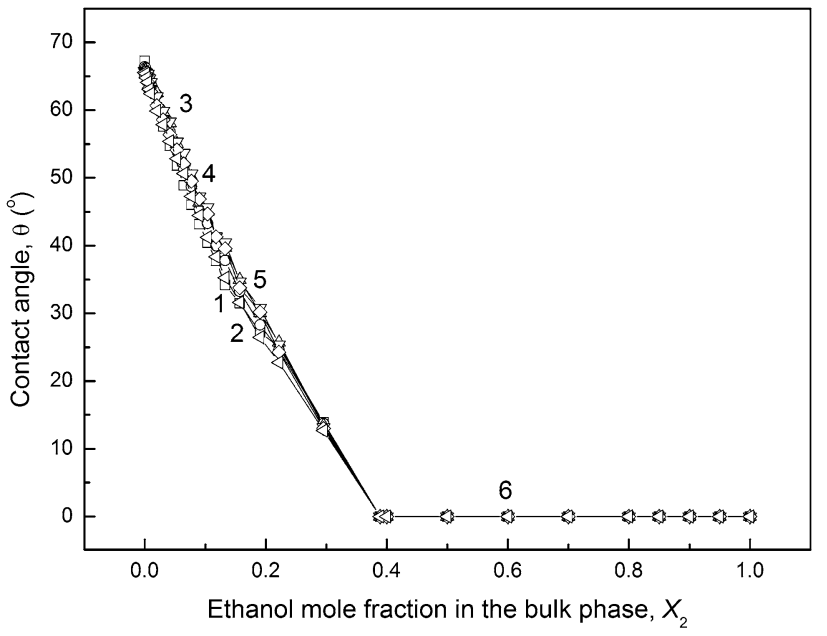

Fig. 2 The plot of the contact angle $(\theta)$ of the aqueous solutions of the TX-100 and CTAB mixture with ethanol at the constant total concentration of the TX-100 and CTAB mixture equal to $1 \times 10^{-5} \mathrm{M}$ versus ethanol mole fraction in the bulk phase $\left(X_{2}\right)$. Curves 1-6 correspond to the mole fraction of TX-100 in the mixture with CTAB equal to $0 ; 0.2 ; 0.4 ; 0.6 ; 0.8$ and 1 , respectively

$\gamma_{S V}-\gamma_{S L}=\gamma_{L V} \cos \theta$

where $\gamma_{S V}$ is the surface tension of the solid covered by the liquid film $\left(\gamma_{S V}=\gamma_{S}-\Pi_{e}\right.$, where $\gamma_{S}$ is the surface tension of the solid and $\Pi_{e}$ is the liquid film pressure on the nylon6 surface), $\gamma_{S L}$ is the solid-liquid interfacial tension, $\gamma_{L V}$ is the surface tension of the liquid and $\theta$ is the contact angle of the liquid on the solid surface.

As follows from the Young's equation, the contact angle of the solution on the nylon- 6 surface depends on the surface

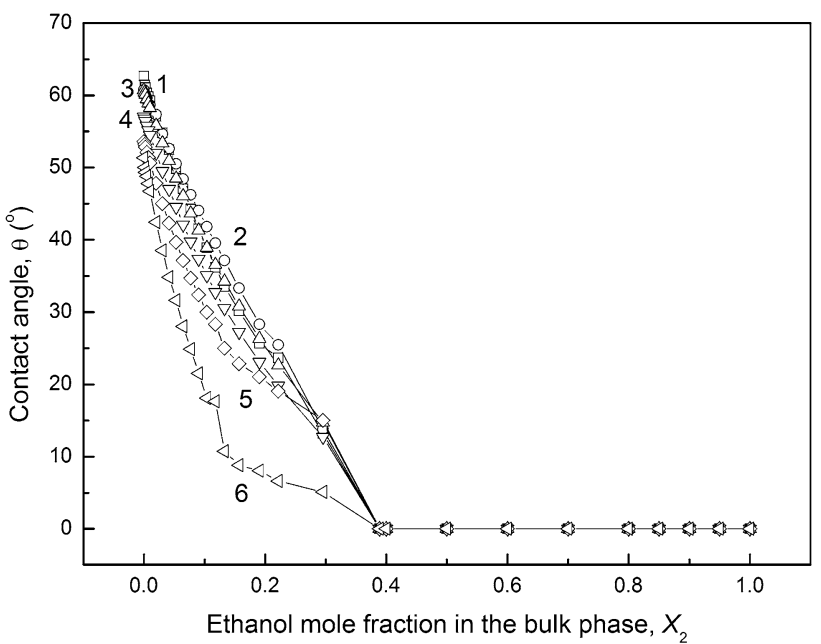

Fig. 3 The plot of the contact angle $(\theta)$ of the aqueous solutions of the TX-100 and CTAB mixture with ethanol at the constant total concentration of the TX-100 and CTAB mixture equal to $1 \times 10^{-4} \mathrm{M}$ versus ethanol mole fraction in the bulk phase $\left(X_{2}\right)$. Curves $1-6$ correspond to the mole fraction of TX-100 in the mixture with CTAB equal to $0 ; 0.2 ; 0.4 ; 0.6 ; 0.8$ and 1 , respectively

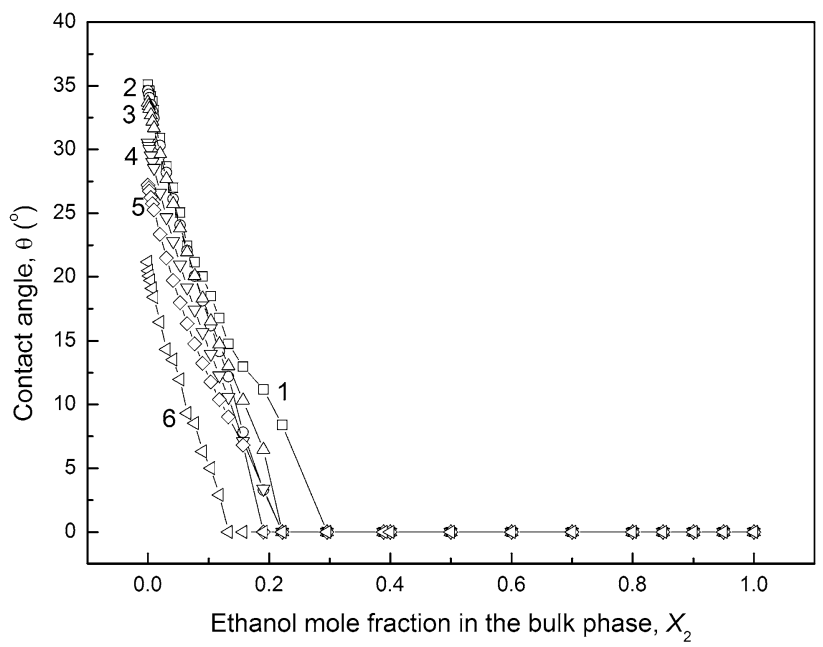

Fig. 4 The plot of the contact angle $(\theta)$ of the aqueous solutions of the TX-100 and CTAB mixture with ethanol at the constant total concentration of the TX-100 and CTAB mixture equal to $1 \times 10^{-3} \mathrm{M}$ versus ethanol mole fraction in the bulk phase $\left(X_{2}\right)$. Curves 1-6 correspond to the mole fraction of TX-100 in the mixture with CTAB equal to $0 ; 0.2 ; 0.4 ; 0.6 ; 0.8$ and 1 , respectively

tensions of nylon- 6 and the solution as well as on the nylon6-solution interfacial tension. However, this equation does not inform us about the influence of different kinds of intermolecular interactions on the wettability of nylon-6. According to van Oss (1994) the nylon-6-solution interfacial tension can be expressed by the following equation:

$\gamma_{S L}=\gamma_{S}+\gamma_{L V}-2 \sqrt{\gamma_{S}^{L W} \gamma_{L V}^{L W}}-2 \sqrt{\gamma_{S}^{+} \gamma_{L V}^{-}}-2 \sqrt{\gamma_{S}^{-} \gamma_{L V}^{+}}$ 
where $\gamma^{L W}$ is the Lifshitz-van der Waals apolar component of the surface tension, $\gamma^{+}$and $\gamma^{-}$are the electron-acceptor and electron-donor parameters of the Lewis acid-base component of the surface tension and the subscripts $S$ and $L V$ refer to the solid and liquid, respectively. Introducing (2) to (1) we obtain:

$\gamma_{L V}(1+\cos \theta)+\Pi_{e}=2\left(\sqrt{\gamma_{S}^{L W} \gamma_{L V}^{L W}}+\sqrt{\gamma_{S}^{+} \gamma_{L V}^{-}}+\sqrt{\gamma_{S}^{-} \gamma_{L V}^{+}}\right)$

As follows from (3), the contact angle depends on the contribution of the Lifshitz-van der Waals and acid-base interactions to the surface tension of nylon- 6 and the aqueous solutions of TX-100 and CTAB mixture with ethanol as well as on the liquid film pressure on the nylon- 6 surface around the drop of the solution settled on its surface. It was shown that the surface tension of nylon- 6 and its Lifshitz-van der Waals component is equal to 40.26 and $36.48 \mathrm{mN} / \mathrm{m}$, respectively (Szymczyk et al. 2012) and that the electronacceptor and electron-donor parameters of the Lewis acidbase component of its surface tension are higher than zero ( 0.25 and $12.83 \mathrm{mN} / \mathrm{m}$, respectively). The electron-donor parameter is higher than its electron-acceptor one which is caused by the presence of the $\mathrm{C}=\mathrm{O}$ groups on its surface but the small value of the electron-acceptor parameter results probably from the presence of N-H groups (Tate et al. 1996). On the other hand, the surface tension of all constituents of the studied solutions results from the Lifshitz-van der Waals and acid-base interactions. However, the Lifshitz-van der Waals components of ethanol (Zdziennicka 2010a), water (Fowkes 1964) and hydrophobic parts of TX-100 (Szymczyk and Jańczuk 2008) and CTAB (Jańczuk et al. 1997) are nearly the same but there are big differences among the electronacceptor and electron-donor parameters of these substances. Therefore, it seems that the wettability of nylon- 6 by the aqueous solutions of TX-100 and CTAB mixture with ethanol at the same surface tension should be different depending on the composition of the surfactant mixture and the concentration of ethanol which is confirmed by the data presented in Figs. 5 and 6. It is in contrast to the suggestions of Neumann et al. (1974) and in accordance to the other investigators (Jańczuk and Białopiotrowicz 1989; van Oss 1994). It is interesting that the minimum of the contact angle occurs at the concentration of the surfactant mixture equal to $1 \times 10^{-6} \mathrm{M}$ and the mole fraction of TX-100 equal to 0.2 , at the constant surface tension of the solution. This minimum corresponds to the maximal synergetic effect in the reduction of the water surface tension by the TX-100 and CTAB mixture in the absence of ethanol (Szymczyk and Jańczuk 2007). However, if the concentration of the TX-100 and CTAB mixture is higher than $1 \times 10^{-6} \mathrm{M}$, there is a positive deviation from the linear dependence of the contact angle on

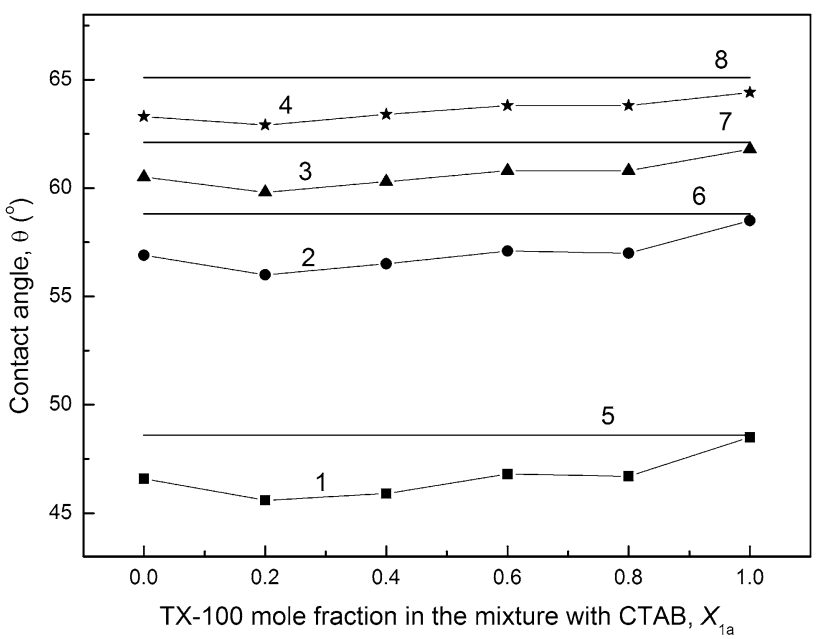

Fig. 5 The dependence between the contact angle $(\theta)$ of the aqueous solutions of the TX-100 and CTAB mixture with ethanol and TX100 mole fraction in the bulk phase $\left(X_{1 \mathrm{a}}\right)$ at the constant total concentration of the TX-100 and CTAB mixture equal to $1 \times 10^{-6} \mathrm{M}$ for the constant surface tension of the solution equal to $40 \mathrm{mN} / \mathrm{m}$ (curve 1), $50 \mathrm{mN} / \mathrm{m}$ (curve 2), $55 \mathrm{mN} / \mathrm{m}$ (curve 3) and $60 \mathrm{mN} / \mathrm{m}$ (curve 4). Curves 5-8 correspond to the contact angle of the aqueous solutions of ethanol at the constant surface tension equal to $40,50,55$, $60 \mathrm{mN} / \mathrm{m}$, respectively

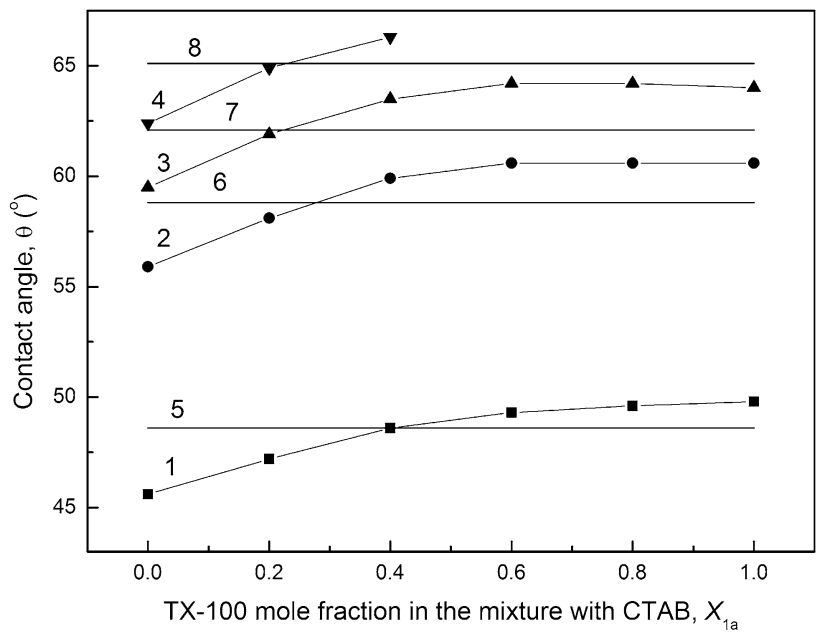

Fig. 6 The dependence between the contact angle $(\theta)$ of the aqueous solutions of the TX-100 and CTAB mixture with ethanol and TX100 mole fraction in the bulk phase $\left(X_{1 \mathrm{a}}\right)$ at the constant total concentration of the TX-100 and CTAB mixture equal to $1 \times 10^{-5} \mathrm{M}$ for the constant surface tension of the solution equal to $40 \mathrm{mN} / \mathrm{m}$ (curve 1), $50 \mathrm{mN} / \mathrm{m}$ (curve 2), $55 \mathrm{mN} / \mathrm{m}$ (curve 3) and $60 \mathrm{mN} / \mathrm{m}$ (curve 4). Curves 5-8 correspond to the contact angle of the aqueous solutions of ethanol at the constant surface tension equal to 40, 50, 55, $60 \mathrm{mN} / \mathrm{m}$, respectively

the surfactant mixture composition at the constant surface tension of the solution. Taking the individual components of the studied solutions into account, the lowest value of the contact angle was obtained for the aqueous solutions of 
CTAB and the highest for the aqueous solutions of TX-100 or ethanol depending on their concentration in the bulk phase. This can be explained on the basis of the work of adhesion of water, ethanol, TX-100 and CTAB $\left(W_{a}\right)$ to the nylon-6 surface calculated from the following equation (Szymczyk et al. 2012; van Oss 1994; Zdziennicka 2010a; Fowkes 1964; Szymczyk and Jańczuk 2008; Jańczuk et al. 1997):

$W_{a}=2\left(\sqrt{\gamma_{S}^{L W} \gamma_{L V}^{L W}}+\sqrt{\gamma_{S}^{+} \gamma_{L V}^{-}}+\sqrt{\gamma_{S}^{-} \gamma_{L V}^{+}}\right)$

Of course, the work of adhesion of CTAB and TX-100 depends on the orientation of their molecules to the nylon-6 surface. Because the electron-donor parameters of the hydrophilic part of TX-100 (Szymczyk and Jańczuk 2008) and nylon-6 (Szymczyk et al. 2012) surface tension are considerably higher than the electron-acceptor ones which have a very small value for both substrates, it is probable that the Lifshitz-van der Waals interactions play the biggest role in the case of TX-100 interactions with nylon-6. The values of the work of adhesion of all constituents of the studied solutions calculated from (4) are listed in Table 1. As follows from this table, CTAB has the strongest preferences for the adsorption on the nylon- 6 surface among all constituents. However, the molecules of alcohol and TX-100 practically cannot remove water molecules from the nylon-6 surface. Taking this fact into account, it results that $\mathrm{CTAB}$ has the biggest contribution to the reduction of nylon-6-solution interfacial tension and therefore the contact angle of the aqueous solutions of $\mathrm{CTAB}$ at the constant surface tension of the solution is the

Table 1 The components and parameters of the surface tension of different substances as well as the work of adhesion of the liquids to the nylon- 6 surface

\begin{tabular}{|c|c|c|c|c|c|}
\hline Component & $\begin{array}{l}\gamma^{L W} \\
(\mathrm{mN} / \mathrm{m})\end{array}$ & $\begin{array}{l}\gamma^{+} \\
(\mathrm{mN} / \mathrm{m})\end{array}$ & $\begin{array}{l}\gamma^{-} \\
(\mathrm{mN} / \mathrm{m})\end{array}$ & $\begin{array}{l}\text { Work of } \\
\text { adhesion } \\
W_{a}\left(\mathrm{~mJ} / \mathrm{m}^{2}\right)\end{array}$ & Reference \\
\hline Water & 21.8 & 25.5 & 25.5 & 97.6 & $\begin{array}{l}\text { Fowkes } \\
\text { (1964) }\end{array}$ \\
\hline Ethanol & 21.4 & 0.09 & 9 & 61.0 & $\begin{array}{l}\text { Zdziennicka } \\
\text { (2010a) }\end{array}$ \\
\hline CTAB-Tail & 27 & 0 & 0 & 62.8 & $\begin{array}{l}\text { Jańczuk et al. } \\
\text { (1997) }\end{array}$ \\
\hline $\begin{array}{r}\text { CTAB- } \\
\text { Head }\end{array}$ & 41.35 & 58.45 & 0 & 132.4 & $\begin{array}{c}\text { Jańczuk et al. } \\
\text { (1997) }\end{array}$ \\
\hline $\begin{array}{l}\text { TX-100- } \\
\text { Tail }\end{array}$ & 22 & 0 & 0 & 56.7 & $\begin{array}{l}\text { Szymczyk and } \\
\text { Jańczuk } \\
(2008)\end{array}$ \\
\hline $\begin{array}{c}\text { TX-100- } \\
\text { Head }\end{array}$ & 21.3 & 1.43 & 49.1 & 71.3 & $\begin{array}{l}\text { Szymczyk and } \\
\text { Jańczuk } \\
(2008)\end{array}$ \\
\hline Nylon-6 & 36.48 & 0.25 & 12.83 & & $\begin{array}{l}\text { Szymczyk } \\
\text { et al. (2012) }\end{array}$ \\
\hline
\end{tabular}

lowest. It seems that at first the CTAB molecules are adsorbed on the "pure" nylon-6 surface and TX-100 and ethanol molecules are only coadsorbed. Obviously, one should remember that not only the changes of the nylon-6solution interfacial tension caused by the adsorption of TX100, CTAB and ethanol molecules affect the contact angle values, but according to (1), the value of the contact angle results from the surface tension of solution as well as from the existence of the liquid film on the nylon- 6 surface. This is confirmed by the comparison of the contact angle, surface tension and nylon-6-solution interfacial tension changes as a function of the ethanol mole fraction in the solution (Fig. 7 as an example). From Fig. 7 it can be clearly seen that the isotherm of the contact angle is somewhat different from those of the surface tension and the nylon-6-solution interfacial tension. Because there is a small difference in the apolar interactions of all constituents of the solution to the nylon- 6 surface therefore the differences between these isotherms should result from the polar interactions of these constituents to the nylon- 6 surface. Moreover, for this reason, the composition of the layer at the nylon-6-solution interface is different from that at the solution-air one. The adsorption of CTAB is higher at the solid-solution interface than at the solution-air one in contrast to TX-100 for which the tendency is opposite (Bielawska et al. 2012).

\subsection{Critical surface tension of nylon-6 wetting}

According to the Young's equation (Adamson and Gast 1997) (Eq. (1)), liquid should spread completely on the solid surface when its surface tension is equal or lower than that of the solid and if the solid-liquid interfacial tension is equal to zero

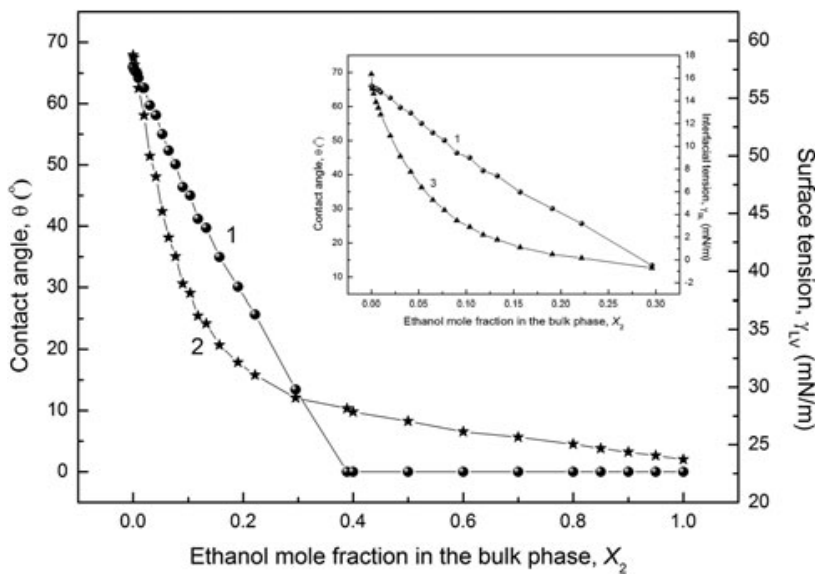

Fig. 7 The dependence between the contact angle $(\theta)$ (curve 1), the surface tension (curve 2) and nylon-6-solution interfacial tension (curve 3) and ethanol mole fraction in the bulk phase $\left(X_{2}\right)$ at the constant concentration of the surfactant mixture equal to $1 \times 10^{-5} \mathrm{M}$ and TX-100 mole fraction in the mixture with CTAB equal to 0.4 
and $\gamma_{S V}=\gamma_{S}$. However, the complete spreading of the aqueous solutions of TX-100 and CTAB mixture with ethanol on the nylon- 6 surface was observed at the surface tension of the solution considerably lower than that of nylon-6. Zisman (1964) proved that complete wetting of the solid surface occurs if the surface tension of the liquid assumes the certain value characteristic for a given solid called by him the critical surface tension of the solid wetting $\left(\gamma_{C}\right)$. It can be determined by the approximation of some relationships to the contact angle equal to zero. For this purpose, the dependences between the cosine of the contact angle or the adhesion tension and the surface tension are usually applied. For the homologous series of apolar liquids, the relationship between the cosine of the contact angle formed by these liquids on the solid and the surface tension of the liquid is usually linear. According to Zisman et al. this assumption is also correct for the aqueous solutions of the surface active agents (Bernett and Zisman 1959a, b). Unfortunately, the $\cos \theta-\gamma_{L V}$ plot for the aqueous solutions of TX-100 and CTAB mixture with ethanol on the nylon- 6 surface is not linear at both the constant surfactant mixture concentration and that of ethanol (Figs. S1S4). However, from our calculations it results that the changes of the cosine of the contact angle as a function of the surface tension of the solution (Figs. S1-S4) can be well approximated by the exponential (Fig. S5) or polynomial (Fig. S6) functions and the critical surface tension of nylon- 6 wetting can be determined by extrapolating these curves to the zero of contact angle. On the basis of these approximations, it can be stated that the value of $\gamma_{C}$ of nylon- 6 at the constant concentration of the surfactant mixture is practically constant $(26.7-28.3 \mathrm{mN} / \mathrm{m})$ and does not depend on the concentration and composition of the surfactant mixture.

According to Bargeman and van Voorst Vader (1973), there is a linear relationship between the adhesion tension $\left(\gamma_{L V} \cos \theta\right)$ and the surface tension of the liquid $\left(\gamma_{L V}\right)$. This relationship was confirmed for the studied solutions, of course only in the range of ethanol concentration in which the complete spreading of the solution on the nylon- 6 surface does not occur, because only in this range the Young's equation is correct (Figs. S7-S10). From the $\gamma_{L V}$ $\cos \theta-\gamma_{L V}$ plot the critical surface tension of nylon-6 wetting can be also determined. The value of $\gamma_{C}$ calculated in this way at the constant concentration of the surfactant mixture is also practically constant and does not depend on the composition and concentration of the surfactant mixture $(26.7-28.6 \mathrm{mN} / \mathrm{m})$. Thus, we can come to the conclusion that the value of $\gamma_{C}$ determined at the constant concentration and composition of the surfactant mixture is constant independently of the way of its evaluation.

However, the critical surface tension of nylon- 6 wetting determined at the constant ethanol concentration depends on its concentration and the composition of the surfactant mixture (Fig. 8). It is interesting that the changes of $\gamma_{C}$ calculated in this way as a function of ethanol concentration can be described by the exponential function (Fig. S11). The minimal $\gamma_{C}$ values obtained at the constant ethanol concentration in the solution are close to the $\gamma_{C}$ value determined at the constant concentration of the surfactant mixture. All the values of the critical surface tension of nylon- 6 wetting obtained from both $\cos \theta-\gamma_{L V}$ and $\gamma_{L V} \cos \theta-\gamma_{L V}$ dependencies at the constant concentration of the TX-100 and CTAB mixture or that of alcohol are lower than the surface tension of nylon-6 and even the Lifshitz-van der Waals component of this tension (Szymczyk et al. 2012).

To show the reason for such correlation between the critical surface tension of nylon- 6 wetting and its surface tension, we considered the possibility of the liquid film formation around the drop of the solution settled on the nylon-6 surface.

According to Girifalco and Good (1957), the relationship between the solid-liquid interfacial tension and the solid and liquid surface tension can be expressed by the following equation:

$\gamma_{S L}=\gamma_{S V}+\gamma_{L V}-2 \phi \sqrt{\gamma_{S V} \cdot \gamma_{L V}}$

Introducing this equation to (1) if $\gamma_{L V}=\gamma_{C}$ we obtain:

$\gamma_{S V}=\frac{\gamma_{C}}{\phi^{2}}$

where $\phi$ is the interfacial interaction parameter.

This parameter consists of two components-apolar and polar. The apolar component is equal to the ratio of the Lifshitz van der Waals interactions between two phases being in contact to the average interaction in each phase and the polar one represents the Lewis acid-base interaction across the interface.

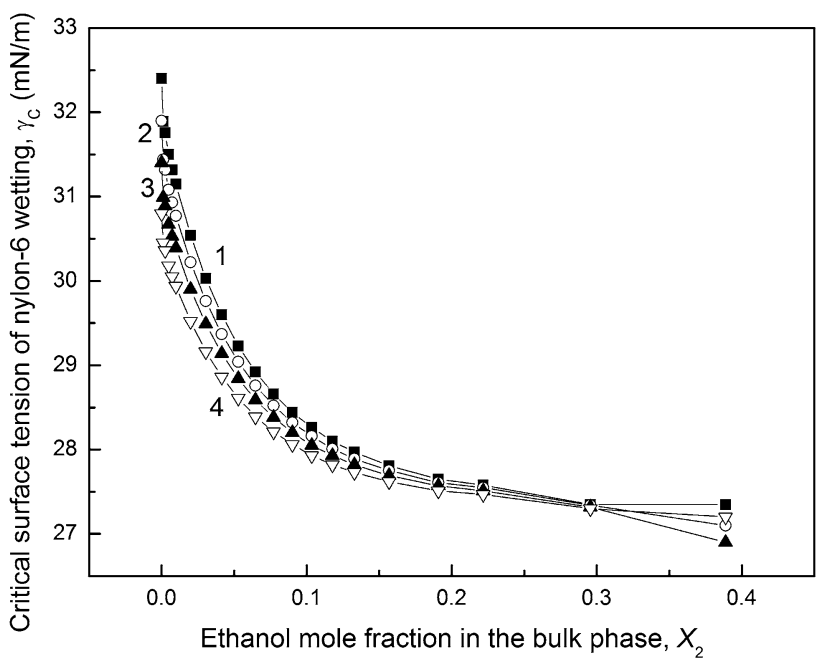

Fig. 8 The dependence between the critical surface tension of nylon6 wetting $\left(\gamma_{C}\right)$ and ethanol mole fraction in the bulk phase $\left(X_{2}\right)$. Curves 1-4 correspond to TX-100 mole fraction in the mixture with $\mathrm{CTAB}$ equal to $0.2 ; 0.4 ; 0.6$ and 0.8 , respectively 
From (6) its results that if $\gamma_{S V}=\gamma_{S}$ and $\phi=1$ then $\gamma_{S}=\gamma_{C}$ or if $\gamma_{S V} \neq \gamma_{S}$ and $\phi=1$ then $\gamma_{S V}=\gamma_{C}$. In our case the surface tension of nylon- 6 is higher than the critical surface tension of its wetting. It means that if $\gamma_{L V}=\gamma_{C}$, then $\gamma_{S} \neq \gamma_{C}$ or $\phi \neq 1$.

\subsection{The adsorption at the nylon-6-solution interface}

To explain this problem, the adsorption of all constituents of the aqueous solutions of the CTAB and TX-100 mixture with ethanol at the solution-air, nylon 6-solution and nylon-6-air interfaces should be considered.

Lucassen-Reynders (1963) derived the equation from which the relationship between the adsorption at three interfaces and the wetting process can be established. It is the combination of (1) and the Gibbs adsorption equation. It has the following form:

$\frac{d\left(\gamma_{L V} \cos \theta\right)}{d \gamma_{L V}}=\frac{\Gamma_{S V}-\Gamma_{S L}}{\Gamma_{L V}}$,

where $\Gamma$ is the surface active agent excess concentration and the subscripts $S V, S L$ and $L V$ refer to the solid-air, solid-liquid and liquid-air interfaces, respectively.

If there is a linear dependence between the adhesion tension and the surface tension of the solution then the ratio of $\left(\Gamma_{S V}-\Gamma_{S L}\right) / \Gamma_{L V}$ does not depend on the concentration of the surface active agent for which that dependence was considered. On the other hand, from this equation we get to know nothing about the surface excess concentration of the surface active agents at the nylon-6-solution and nylon-6air interfaces. It is possible to establish this concentration directly from the Gibbs adsorption equation. If the surface tension of nylon- 6 is constant, this equation for the surface excess concentration of ethanol at the constant concentration of the TX-100 and CTAB mixture at the nylon-6solution interface has the following form:

$\Gamma_{S L}=-\frac{a_{v}}{R T}\left(\frac{-\partial \gamma_{L V} \cos \theta}{\partial a_{v}}\right)_{C_{1}}$

where $a_{v}$ is the activity of ethanol in the bulk phase of solution, $R$ is the gas constant and $T$ is the temperature.

However, if the surface tension of nylon- 6 depends on the ethanol concentration or, in other words, the film of ethanol vapors is formed on nylon- 6 around the solution drop settled on its surface then (8) should be expressed as:

$\Gamma_{S L}=-\frac{a_{v}}{R T}\left(\frac{\partial\left(\gamma_{S V}-\gamma_{L V} \cos \theta\right)}{\partial a_{v}}\right)_{C_{1}}$

It is known that the equilibrium pressure of any constituent of the solution is proportional to its activity in the bulk phase. Thus, it is possible to assume, at the first approximation, that the decrease of the nylon- 6 surface tension by the ethanol film is related to its activity in the bulk phase. In such case the surface excess concentration of ethanol at the nylon-6-air interface should fulfill the equation:

$\Gamma_{S V}=-\frac{a_{v}}{R T}\left(\frac{\partial \gamma_{S V}}{\partial a_{v}}\right)_{C_{1}}$

If the surface excess concentration of ethanol is calculated from (8) (Figs. 9, 10, 11, 12), the minimum of the surface excess concentration is observed at its concentration in the bulk phase corresponding to the maximum on the ethanol adsorption isotherm at the solution-air interface (Yano 2005). Moreover, at the concentration of the surfactant mixture equal to $1 \times 10^{-3} \mathrm{M}$, the surface excess concentration of ethanol takes the negative value in the whole range of ethanol concentration. On the other hand, the ratio $\Gamma_{S L} / \Gamma_{L V}$ depends on the alcohol and surfactant mixture concentration and is quite different from the slope of $\gamma_{L V} \cos \theta-\gamma_{L V}$ dependence. It means that the surface tension of nylon- 6 changes as a function of ethanol concentration and $\Gamma_{S V}>0$.

Assuming that ethanol molecules are adsorbed around the drop of the aqueous solution of TX-100 and CTAB mixture with ethanol settled on the nylon- 6 surface and that the molecules of surfactants do not migrate from the drop to this surface, then the surface tension of nylon- 6 should change as a function of ethanol concentration. On the other hand, it is known that the partial pressure of ethanol over the solution is proportional to its activity in the surface layer at the solution-air interface. Thus, it should be expected that in the nylon-6-solution drop-air system being in equilibrium, the activity of ethanol in the surface layer at the nylon-6-air interface is comparable to its activity in the surface layer at the solution-air interface. If so, the surface tension of nylon- 6 covered by the adsorbed ethanol molecules should change proportionally to the changes of the water surface tension affected by the ethanol adsorption at the water-air interface. Therefore, we assumed that the surface tension of nylon- 6 should change under the influence of the adsorbed ethanol molecules on its surface from the value of the surface tension of "pure" nylon- 6 to that of the critical surface tension of nylon- 6 wetting determined at the constant concentration of surfactant mixture. The $\gamma_{S V}$ values established in such a way were used for the calculation of $\Gamma_{S L}$ in (9) and $\Gamma_{S V}$ in (10).

It turned out that all the isotherms calculated from (9) have the classical shape of the Gibbs adsorption isotherm of alcohol and the surface excess concentration of ethanol is much higher than in the case in which we assumed the constant surface tension of nylon-6.

Unexpectedly, if $\Gamma_{S V}$ was calculated from (10) on the assumption that ethanol film is present around the solution drop settled on the nylon- 6 surface decreasing its surface tension and $\Gamma_{S L}$ was calculated from (9), then the value of 


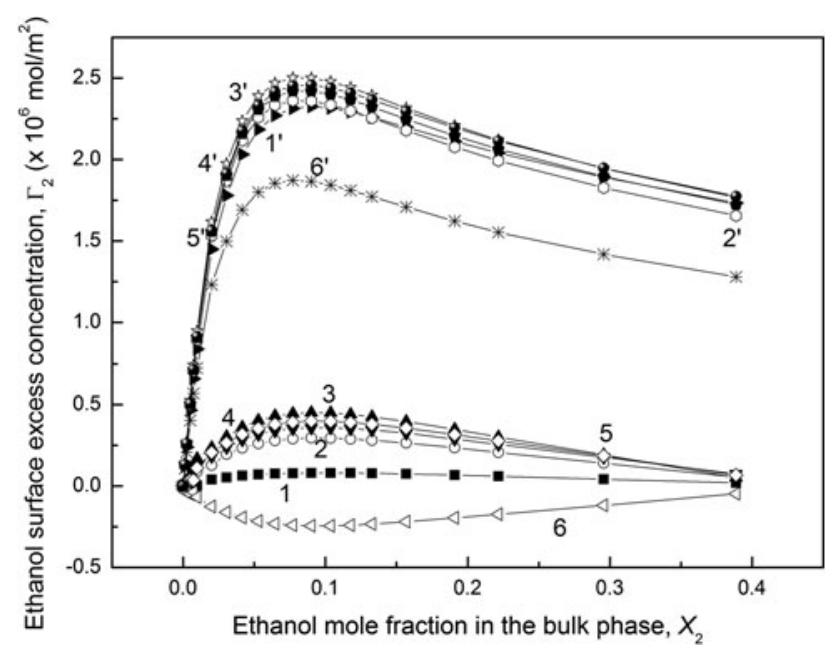

Fig. 9 The dependence between ethanol surface excess concentration $\left(\Gamma_{2}\right)$ at the nylon-6-solution interface and ethanol mole fraction in the bulk phase $\left(X_{2}\right)$ calculated from (8) (curves 1-6) and (9) (curves $1^{\prime}-6^{\prime}$ ) at the constant total concentration of the TX-100 and CTAB mixture equal to $1 \times 10^{-6} \mathrm{M}$. Curves 1 and $1^{\prime}, 2$ and $2^{\prime}, 3$ and $3^{\prime}, 4$ and $4^{\prime}, 5$ and $5^{\prime}, 6$ and $6^{\prime}$ correspond to the TX-100 mole fraction in the mixture with $\mathrm{CTAB}$ equal to $0,0.2,0.4,0.6,0.8$ and 1 , respectively

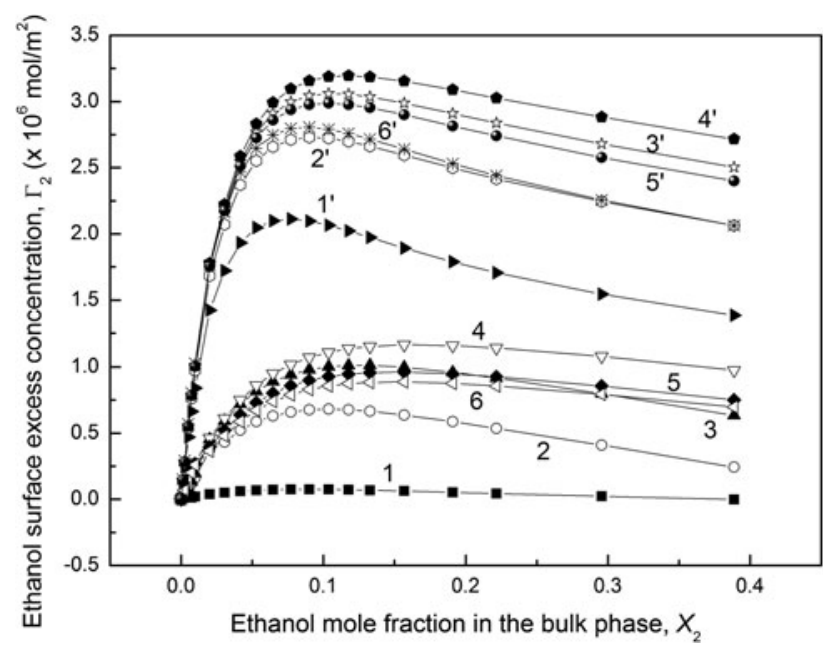

Fig. 10 The dependence between ethanol surface excess concentration $\left(\Gamma_{2}\right)$ at the nylon-6-solution interface and ethanol mole fraction in the bulk phase $\left(X_{2}\right)$ calculated from (8) (curves 1-6) and (9) (curves $\left.1^{\prime}-6^{\prime}\right)$ at the constant total concentration of the TX-100 and CTAB mixture equal to $1 \times 10^{-5} \mathrm{M}$. Curves 1 and $1^{\prime}, 2$ and $2^{\prime}, 3$ and $3^{\prime}, 4$ and $4^{\prime}, 5$ and $5^{\prime}, 6$ and $6^{\prime}$ correspond to the TX-100 mole fraction in the mixture with $\mathrm{CTAB}$ equal to $0,0.2,0.4,0.6,0.8$ and 1 , respectively

$\left(\Gamma_{S V}-\Gamma_{S L}\right) / \Gamma_{L V}$ determined at the constant ethanol concentration as a function of the TX-100 and CTAB mixture is very close to the slope of the linear dependence between the adhesion tension and the surface tension. It should be remembered that in the range of alcohol concentration in which the complete spreading of the solution over the nylon-6 surface takes place, it is difficult to establish the surface excess concentration of ethanol at the nylon-6-

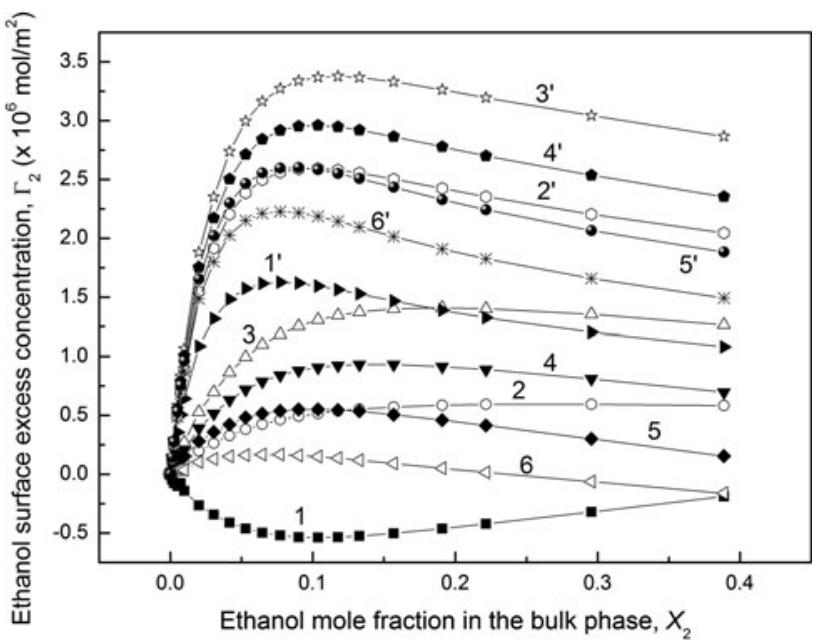

Fig. 11 The dependence between ethanol surface excess concentration $\left(\Gamma_{2}\right)$ at the nylon-6-solution interface and ethanol mole fraction in the bulk phase $\left(X_{2}\right)$ calculated from (8) (curves 1-6) Eq. (9) (curves $\left.1^{\prime}-6^{\prime}\right)$ at the constant total concentration of the TX-100 and CTAB mixture equal to $1 \times 10^{-4} \mathrm{M}$. Curves 1 and $1^{\prime}, 2$ and $2^{\prime}, 3$ and $3^{\prime}, 4$ and $4^{\prime}, 5$ and $5^{\prime}, 6$ and $6^{\prime}$ correspond to the TX-100 mole fraction in the mixture with CTAB equal to $0,0.2,0.4,0.6,0.8$ and 1 , respectively

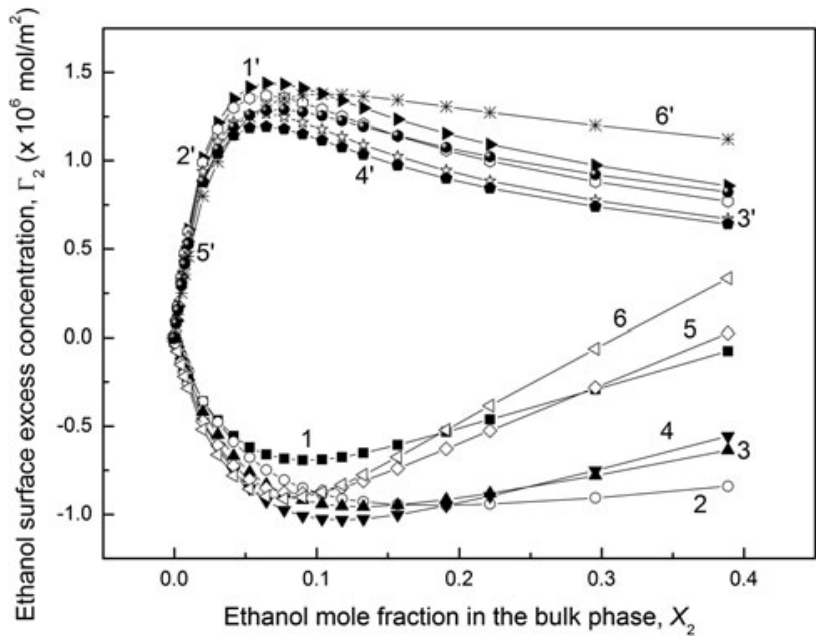

Fig. 12 The dependence between ethanol surface excess concentration $\left(\Gamma_{2}\right)$ at the nylon-6-solution interface and ethanol mole fraction in the bulk phase $\left(X_{2}\right)$ calculated from (8) (curves 1-6) Eq. (9) (curves 1'-6 $1^{\prime}$ ) at the constant total concentration of the TX-100 and CTAB mixture equal to $1 \times 10^{-3}$ M. Curves 1 and $1^{\prime}, 2$ and $2^{\prime}, 3$ and $3^{\prime}, 4$ and $4^{\prime}, 5$ and $5^{\prime}, 6$ and $6^{\prime}$ correspond to the TX-100 mole fraction in the mixture with $\mathrm{CTAB}$ equal to $0,0.2,0.4,0.6,0.8$ and 1 , respectively

solution interface because the Young's equation is not fulfilled in this concentration range.

Moreover, it can be stated that the adsorption of ethanol at the nylon-6-solution interface is much lower than at the solution-air one and that the adsorption at these interfaces decreases with the increasing concentration of the surfactant mixture. Unfortunately, on the basis of our studies it is difficult to determine the surface excess concentration of the TX-100 and CTAB mixture at the 
nylon-6-solution interface and on the basis of $\gamma_{C}$ changes we can only state that the adsorption of the TX-100 and CTAB mixture at the nylon-6-solution interface is lower than that at the solution-air one and the ratio of $\Gamma_{S L} / \Gamma_{L V}$ of the surfactant mixture decreases as the ethanol concentration increases.

\section{Conclusions}

On the basis of the contact angle measurements and the discussion of the obtained results it can be stated that:

The biggest changes of the contact angle take place in the range of ethanol and the TX-100 and CTAB mixture concentration in which they are present in the monomeric form in the solution.

The complete spreading of the aqueous solutions of the TX-100 and CTAB mixture with ethanol on the nylon-6 surface occurred at the surface tension of the solution considerably lower than that of nylon- 6 and it practically does not depend on the concentration of the TX-100 and CTAB mixture.

The critical surface tension of nylon- 6 wetting at the constant concentration of the TX-100 and CTAB mixture does not depend on its concentration It is also lower than the surface tension of nylon- 6 and even the Lifshitz-van der Waals component of this tension.

The critical surface tension of nylon- 6 wetting at the constant ethanol concentration depends on its concentration and the composition of the TX-100 and CTAB mixture. The critical surface tension of nylon- 6 wetting changes as a function of ethanol concentration from the values of $\gamma_{C}$ obtained for the aqueous solutions of individual surfactants to the value of $\gamma_{C}$ obtained at the constant concentration of the surfactant mixture.

The ethanol film is present around the solution drop settled on the nylon- 6 surface and it decreases its surface tension.

The ratio of the difference between the surface excess concentration of ethanol at the nylon-6-air and nylon-6solution interfaces to the solution-air one is constant for a given concentration of the TX-100 and CTAB mixture and close to the slope of the linear dependence between the adhesion tension and the surface tension of the solution.

The surface excess concentration of ethanol at the nylon-6-solution interface is considerably lower than that at the solution-air one.

Acknowledgments The financial support from the Polish Ministry of Science and Higher Education, Project No. N204 352040 is gratefully acknowledged.

Open Access This article is distributed under the terms of the Creative Commons Attribution License which permits any use, distribution, and reproduction in any medium, provided the original author(s) and the source are credited.

\section{References}

Adamson, A.W., Gast, A.P.: Physical Chemistry of Surfaces, 6th edn. Wiley-Interscience, New York (1997)

Barchlui, R., Pottel, R.: Counterion contribution to the dielectric spectrum of aqueous solutions of ionic surfactant micelles. J. Phys. Chem. 98, 7899-7905 (1994)

Bargeman, D., van Voorst Vader, F.: Effect of surfactants on contact angles at nonpolar solids. J. Colloid Interface Sci. 42, 467-472 (1973)

Bernett, M.K., Zisman, W.A.: Relation of wettability by aqueous solutions to the surface constitution of low-energy solids. J. Phys. Chem. 63, 1241-1246 (1959a)

Bernett, M.K., Zisman, W.A.: Wetting of low-energy solids by aqueous solutions of highly fluorinated acid and salts. J. Phys. Chem. 63, 1911-1916 (1959b)

Bielawska, M., Jańczuk, B., Zdziennicka, A.: Behavior of cetyltrimethylammonium bromide, tert-octylphenol (9.5 EO) ethoxylate and ethanol mixtures at the water-air interface. J. Surfactants Deterg. (2012). doi:10.1007/s11743-012-1379-3

Blake, T.D.: Wetting. In: Tadros, Th.F. (ed.) Surfactants. Academic Press, London (1984)

Carpena, P., Agular, J., Bernaola-Galván, P., Carnero Ruiz, C.: Problems associated with the treatment of conductivity-concentration data in surfactant solutions: simulations and experiments. Langmuir 18(16), 6054-6058 (2002)

Czerniawski, M.: A study of double layer structure of colloidal electrolytes. IV. Determination of thermodynamic charge on the micelles surface of CTAB, CpyB and DDNH3Cl. Roczniki Chem. 40, 1265-1271 (1966). (in polish)

Das, Ch., Das, B.: Thermodynamic and interfacial adsorption studies on the micellar solutions of alkyltrimethylammonium bromides in ethylene glycol (1) + water (2) mixed solvent media. J. Chem. Eng. Data 54, 559-565 (2009)

Fowkes, F.M.: Attractive forces at interfaces. Ind. Eng. Chem. 56(12), 40-56 (1964)

Girifalco, L.A., Good, R.J.: A theory for the estimation of surface and interfacial energies. I. Derivation and application to interfacial tension. J. Phys. Chem. 61, 904-909 (1957)

Jańczuk, B., Białopiotrowicz, T.: Surface free-energy components of liquids and low energy solids and contact angles. J. Colloid Interface Sci. 127, 189-204 (1989)

Jańczuk, B., Zdziennicka, A., Wójcik, W.: Relationship between wetting of Teflon by cetyltrimethylammonium bromide solution and adsorption. Eur. Polym. J. 33, 1093-1098 (1997)

Jones, M.N.: Surfactants in membrane solubilisation. Int. J. Pharm. 177, 137-159 (1999)

Kahlweit, M., Busse, G., Jen, J.: Adsorption of amphiphiles at water/ air interfaces. J. Phys. Chem. 95, 5580-5586 (1991)

Kumbhakar, M., Nath, S., Mukhrjee, T., Pal, H.: Solvation dynamics in Triton-X-100 and Triton-X-165 micelles: effect of micellar size and hydration. J. Chem. Phys. 121, 6026-6033 (2004)

Leja, J.: Surface Chemistry of Froth Flotation, chaps. 5, 8 and 9. Plenum Press, New York (1982)

Lucassen-Reynders, E.H.: Contact angles and adsorption on solids. J. Phys. Chem. 67, 969-972 (1963)

Musselman, S.W., Chander, S.: Adsorption of acetylenic diol-based nonionic surfactants on lampblack and phthalocyanine blue pigment. J. Colloid Interface Sci. 256, 91-99 (2002)

Nagarajan, R., Wang, Ch.: Theory of surfactant aggregation in water/ ethylene glycol mixed solvents. Langmuir 16(12), 5242-5251 (2000) 
Neumann, A.W., Good, R.J., Hope, C.J., Sejpal, M.: An equation-ofstate approach to determine surface tensions of low-energy solids from contact angles. J. Colloid Interface Sci. 49, 291-304 (1974)

Rhabi, Y., Winnik, M.A.: Solute exchange between surfactant micelles by micelle fragmentation and fusion. Adv. Colloid Interface Sci. 89-90, 25-46 (2001)

Rosen, M.J.: Surfactants and Interfacial Phenomena. Wiley-Interscience, New York (2004)

Szymczyk, K.: The properties of binary mixtures of ethoxylated octyl phenols with ethoxylated fluorinated alkanols at the water/air interface. J. Surfactants Deterg. 14, 415-423 (2011)

Szymczyk, K.: Composition of multicomponent surfactant systems at the water-air interface. J. Surfactants Deter. 15, 647-656 (2012)

Szymczyk, K., Jańczuk, B.: The adsorption at solution-air interface and volumetric properties of mixtures of cationic and nonionic surfactants. Colloid Surf. A 293, 39-50 (2007)

Szymczyk, K., Jańczuk, B.: Wettability of a glass surface in the presence of two nonionic surfactant mixtures. Langmuir 24(15), 7755-7760 (2008)

Szymczyk, K., Jańczuk, B.: A study of the interaction of ternary surfactant systems at the water-air interface. Langmuir 26(4), 2491-2496 (2010)

Szymczyk, K., Zdziennicka, A., Krawczyk, J., Jańczuk, B.: Wettability, adhesion, adsorption and interface tension in the polymer/ surfactant aqueous solution system. I. Critical surface tension of polymer wetting and its surface tension. Colloids Surf. A $\mathbf{4 0 2}$, 132-138 (2012)

Tadros, T.F.: Surfactants in Agrochemicals. Marcel Dekker, New York (1994)

Tandford, C., Reynolds, J.A.: Characterization of membrane proteins in detergent solutions. Biochim. Biophys. Acta 457, 133-170 (1976)

Tate, M.L., Kamath, Y.K., Wesson, S.P., Ruetsch, S.B.: Surface energetics of nylon 66 fibers. J. Colloid Interface Sci. 177, 579-588 (1996) van Oss, C.J.: Interfacial Forces in Aqueous Media. Marcel Dekker, New York (1994)

Vogel, A.I.: Preparatyka organiczna, wyd. 3. WNT, Warszawa (2006)

Yano, Y.F.: Correlation between surface and bulk structures of alcoholwater mixtures. J. Colloid Interface Sci. 284, 255-259 (2005)

Zana, R.: Aqueous surfactant-alcohol systems: a review. Adv. Colloid Interface Sci. 57, 1-64 (1995)

Zdziennicka, A.: The adsorption properties of short chain alcohols and Triton X-100 mixtures at the water-air interface. J. Colloid Interface Sci. 335, 175-182 (2009a)

Zdziennicka, A.: The wettability of polytetrafluoroethylene and polymethylmethacrylate by aqueous solutions of Triton X-100 and short chain alcohol mixtures. Appl. Surf. Sci. 255, 7369-7379 (2009b)

Zdziennicka, A.: Surface behavior of Triton X-165 and short chain alcohol mixtures. Langmuir 26(2), 1860-1869 (2010a)

Zdziennicka, A.: The wettability of polytetrafluoroethylene and polymethylmethacrylate with regard to interface behaviour of Triton X-165 and short chain alcohol mixtures: I. Critical surface tension of wetting and adhesion work. Colloids Surf. A 367, 108-114 (2010b)

Zdziennicka, A., Jańczuk, B.: Behaviour of cationic surfactants and short chain alcohols in mixed surface layers at water-air and polymer-water interfaces with regard to polymer wettability. II wettability of polymers. J. Colloid Interface Sci. 350, 568-576 (2010)

Zdziennicka, A., Szymczyk, K., Krawczyk, J., Jańczuk, B.: Critical micelle concentration of some surfactants and thermodynamic parameters of their micellization. Fluid Phase Equilib. 322, 126-134 (2012)

Zisman, W.A.: Contact angle, wettability and adhesion. Adv. Chem. Ser. 43, 1-51 (1964) 